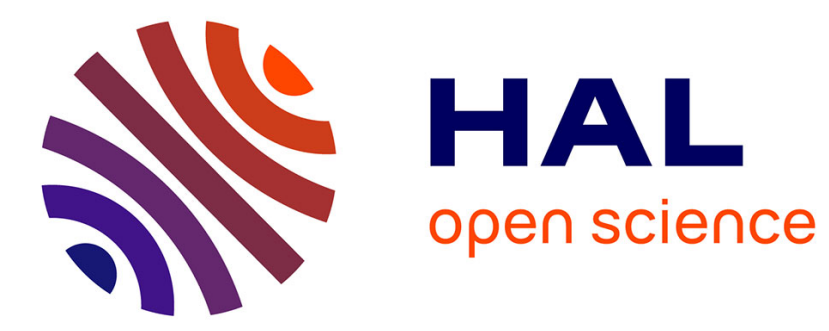

\title{
Incomplete markets, liquidation risk and the term structure of interest rates
}

Edouard Challe, François Le Grand, Xavier Ragot

\section{To cite this version:}

Edouard Challe, François Le Grand, Xavier Ragot. Incomplete markets, liquidation risk and the term structure of interest rates. 2007. halshs-00587679

\section{HAL Id: halshs-00587679 \\ https://shs.hal.science/halshs-00587679}

Preprint submitted on 21 Apr 2011

HAL is a multi-disciplinary open access archive for the deposit and dissemination of scientific research documents, whether they are published or not. The documents may come from teaching and research institutions in France or abroad, or from public or private research centers.
L'archive ouverte pluridisciplinaire HAL, est destinée au dépôt et à la diffusion de documents scientifiques de niveau recherche, publiés ou non, émanant des établissements d'enseignement et de recherche français ou étrangers, des laboratoires publics ou privés. 


\section{PARIS SCHOOL OF ECONOMICS}

WORKING PAPER N 2007 - 49

Incomplete markets, liquidation risk

and the term structure of interest rates

Edouard Challe

François Le Grand

Xavier Ragot

JEL Codes: E21, E43, G12

Keywords: incomplete markets, yield curve, credit constraints 


\title{
Incomplete markets, liquidation risk, and the term structure of interest rates*
}

\author{
Edouard Challe $\quad$ François Le Grand Xavier Ragot ${ }^{\dagger}$
}

\begin{abstract}
We construct a general equilibrium model with incomplete markets and borrowing constraints, in order to study the term structure of real interest rates. Agents are subject to both aggregate and idiosyncratic income shocks, which latter may force them into early portfolio liquidation whilst in recession. We derive a closed-form equilibrium with limited agents' heterogeneity (despite market incompleteness), which allows us to derive analytical expressions for bond prices and returns at any maturity. The desirability of bonds as liquidity makes the aggregate bond demand downward-sloping. One consequence of this is that a larger bond supply raises both the level and the slope of the yield curve.
\end{abstract}

Keywords: incomplete markets, yield curve, credit constraints.

JEL codes: E21, E43, G12.

\footnotetext{
*Acknowledgments: We are indebted to Yann Algan, Gabrielle Demange, François Gourio, Guy Laroque, Caroline Mueller, and Monika Piazzesi for helpful suggestions. We also thank participants at the PSE Lunch seminar, at the joint HEC-INSEAD-PSE Workshop, at the 2007 Meeting of the Society for Economic Dynamics, and at the 2007 ESEM Conference for valuable comments. Financial support from the French National Research Agency is also gratefully acknowledged.

${ }^{\dagger}$ Challe: CNRS and University of Paris-Dauphine, edouard.challe@dauphine.fr. Le Grand: Paris School of Economics and Barclays Capital, Paris, legrand@pse.ens.fr and francois.legrand@barclayscapital.com. Ragot: CNRS and Paris School of Economics, ragot@pse.ens.fr.
} 


\section{Introduction}

Incomplete markets models have frequently been argued to overcome some of the difficulties encountered by the representative agent framework. They notably contribute to explain important features of asset prices, such as the level of the risk-free rate (Huggett (1993)), the size of the equity premium (Constantinides and Duffie (1996)), or the existence of money (Bewley (1983); Scheinkman and Weiss (1986)). These contributions are based on the central idea that market incompleteness introduces a specific motive for demanding (and actually trading) available assets, since those are used to smooth out the idiosyncratic fluctuations that agents face.

Despite the potential insights to be gained, the term structure of interest rates studied under complete markets in the seminal article of Cox, Ingersoll, and Ross (1985), has been the subject of a surprisingly small number of studies with uninsurable idiosyncratic shocks. One potential explanation is the inherent complexity of infinite-horizon, incomplete market models with a large number of assets. On the one hand, market incompleteness usually implies that agents' wealth and optimal decisions depend on the whole history of idiosyncratic income shocks, so that infinitely many types of agents (and associated Euler equations) coexist in the economy. This usually precludes the derivation of analytical expressions and general conclusions about asset prices, except in very special cases such as the paper of Constantinides and Duffie (1996) or the deterministic liquidity constrained model of Kehoe and Levine (2001). On the other hand, the very nature of computational techniques, when applied to models with uninsurable income shocks limits their scope to the study of approximate equilibria with a limited number of assets, typically one or two (as in Krusell and Smith (1997)).

In this paper, we analyze the term structure of real interest rates within an incomplete market, general equilibrium model that features a single good, as well as both infinitely-lived agents and arbitrarily many bond maturities. We manage to do so by assuming a specific implication of uninsurable income shocks: After a fall in current individual income, agents are supposed to liquidate all their assets. In our model, such an asset liquidation by low-income agents is obtained if their ability to trade assets is restricted by an (exogenously imposed) debt limit. We concentrate on a particular equilibrium where asset liquidation is full, in the sense that agents facing a drop in their current earnings liquidate their bond portfolio entirely. As we show, the implied dynamic equilibrium allows us to characterize analytically the entire term structure of interest rates (including prices, yields, and returns of arbitrarily long bonds).

The main features of our model are as follows. The idiosyncratic income risk is specified as a random switch of agents' status between 'employment' and 'unemployment'. Unemployed agents earn a (low) home production income, while employed agents rent out their labor services to a constant return-to-scale firm hit by aggregate productivity shocks. Agents' attempts to smooth out their labor income fluctuations result in twofold consequences. (i) When employed, employed agents accumulate bonds for self-insurance purposes, and (ii) when falling into unemployed, they liquidate them. To close the model, we assume that the government constantly renews stocks of 
zero-coupon bonds of all maturities. The deterministic final payment of bonds is financed through taxes that are designed to minimize distortions.

Given this market structure, we start our analysis by establishing the existence conditions for an equilibrium with full asset liquidation to prevail. This allows us to demonstrate the existence of an equilibrium price system with arbitrarily many maturities, in the case where both aggregate uncertainty and the total net supply of bonds are small (proposition 1).

We ask then the following question: How does the shape of the yield curve change as the net supply of bonds changes? Our first result is that the aggregate bond demand is downward-sloping: Increasing the supply of bonds of any maturity lowers the price of all bonds, that is, it raises the entire yield curve. This effect is easily understood from the liquidity role played by bonds in our economy. More specifically, the conjunction of idiosyncratic income risk with trade restrictions (i.e., debt limits) induces high-income agents to hold bonds of any maturity for precautionary purposes. In this context, more liquidity lowers its desirability and equilibrium prices. Since bonds of various maturities are partly substitute of each other, raising the supply of one particular type of bonds must lower the price of all bonds.

Our second result states that a larger bond supply steepens the yield curve. The result bears upon the relative prices of bonds with different maturities, that is, the risk premia associated with each bond. In our model, risk premia differ across bonds because agents may be forced into liquidating assets before maturity, when their selling price is low due to the aggregate uncertainty. Since the risk of early liquidation increases with the bond maturity, long bonds must command a higher premium in equilibrium than comparatively shorter ones. We then show that raising the supply of bonds of any maturity raises the slope of the yield curve because it sharpens the variability of the liquidation value of agents' portfolio. Thus, both the level and the slope of the yield curve tend to rise as the supply of bonds increases (proposition 2 ). ${ }^{1}$

We end the paper by analyzing the welfare properties of our incomplete market model. More specifically, we establish that while increasing the quantity of bonds of any maturity unambiguously raises ex ante welfare (i.e., from the point of view of date 0 , before agents know their type), it may decrease the welfare of some agents, when they are already aware of their type (proposition 3 ). In a very simple way, employed agents who have to buy assets for self-insurance may suffer from a larger supply; since they have to bear higher taxes.

The rest of paper is organized as follows. Section 2 introduces our framework. The third section describes the equilibrium with full asset liquidation, while Section 4 establishes the conditions for its existence. Section 5 studies the impact of changes in the bond supply on the shape of the yield curve. Section 6 derives the welfare properties of the model, and Section 7 discusses further results, which can be derived within this framework, and concludes.

\footnotetext{
${ }^{1}$ See Fleming (2002) for empirical evidence about the impact of the net bond supply on the yield curve consistent with these results. See also Jegadeesh (2002) for a more general discussion of this evidence.
} 


\section{The economy}

\subsection{Individual and aggregate states}

In every period, each agent can be in either of two states, 'employed' or 'unemployed'. Let $e_{t}^{i}$ denote the status of the agent $i$ at date $t$. The process $e_{t}^{i}=1$ if the agent is employed and $e_{t}^{i}=0$ if the agent is unemployed. Each agent's employment status on the labor market evolves independently according to a first-order Markov chain with the following transition matrix:

$$
\Pi=\left[\begin{array}{cc}
\alpha & 1-\alpha \\
1-\rho & \rho
\end{array}\right], \quad(\alpha, \rho) \in(0,1)^{2},
$$

where $\alpha$ is the probability that an employed agent stays employed in the next period and $\rho$ is the probability that an unemployed agent stays unemployed in the next period.

The initial probability distribution is represented by a row vector $\omega_{0}=\left[\begin{array}{ll}\omega_{0}^{e} & \omega_{0}^{u}\end{array}\right]$, i.e. $\omega_{0}^{e}\left(\omega_{0}^{u}\right.$ respectively) is the probability at date 0 that the agent $i$ is employed (unemployed). Thanks to this simple Markovian structure, the probability distribution at date $t$ is $\omega_{0} \Pi^{t}$, which converges for $t \rightarrow \infty$ towards the invariant distribution $\omega=\left[\begin{array}{ll}\omega^{e} & \omega^{u}\end{array}\right]$, where:

$$
\omega^{e}=(1-\rho)(2-\rho-\alpha)^{-1}, \omega^{u}=(1-\alpha)(2-\rho-\alpha)^{-1}
$$

To simplify the exposition, we assume that $\omega_{0}=\omega$ (i.e., the initial proportions of employed and unemployed agents are given by the invariant distribution).

The history of individual shocks up to date $t$ is denoted by $e^{i, t}$, where $e^{i, t}=\left\{e_{0}^{i}, \ldots, e_{t}^{i}\right\} \in$ $\{0,1\}^{t}=E^{t}$. $E^{t}$ is the set of all possible individual histories up to date $t$, and $\mu_{t}^{i}: E^{t} \rightarrow[0,1], t=$ $0,1, \ldots$ denotes the probability measure of individual histories, consistent with the transition matrix $\Pi$ and with the initial probability distribution $\omega$. For example, $\mu_{t}^{i}\left(e^{i, t}\right)$ is the probability that the agent $i$ experiences the history $e^{i, t}$ at date $t$. We use the notation $e^{i, t+1} \succeq e^{i, t}$ to indicate that $e^{i, t+1}$ is a possible continuation of $e^{i, t}$.

The economy faces an aggregate (technology) shock, whose value at date $t$ is $h_{t}$. The value taken by this shock can be either high $\left(h_{t}=h\right)$ or low $\left(h_{t}=l\right)$. Let $h^{t}=\left\{h_{0}, \ldots, h_{t}\right\}$ denote the history of aggregate shocks from date 0 to date $t$, and $H^{t}$ be the set of all such possible histories. The aggregate shock evolves according to a first-order Markov chain with transition matrix $T$ :

$$
T=\left[\begin{array}{cc}
\pi^{h} & 1-\pi^{h} \\
1-\pi^{l} & \pi^{l}
\end{array}\right]
$$

Moreover, we make the following assumption:

Assumption A $\pi^{h}+\pi^{l}>1$.

The assumption $\mathrm{A}$ is a statement about the persistence of aggregate shocks. In words, the economy does not fluctuate too quickly between both aggregate states. While not necessary for the 
derivation of most of our results, it allows us to avoid discussing some uninteresting cases arising with rapidly alternating states ${ }^{2}$.

The invariant distribution associated with the transition matrix $T$ is denoted $\Phi=\left[\Phi_{l} \Phi_{h}\right]$. We assume that the initial probability distribution across both aggregate states is $\Phi$. We denote $\nu_{t}$ the probability measure over histories up to date $t$, consistent with the transition matrix $T$, and the initial distribution $\Phi: \nu_{t}: H^{t} \rightarrow[0,1], t=0,1, \ldots$ Finally, we denote by $\nu_{t}\left(h^{t}\right)$ the probability that the history $h^{t}$ occurs, and $h^{t+1} \succeq h^{t}$ indicates that $h^{t+1}$ is a possible continuation of $h^{t}$.

\section{$2.2 \quad$ Assets and market structure}

We posit a sharp form of market incompleteness by assuming that individual agents cannot issue any financial securities. This has three significant implications. First, no asset provides a payoff contingent on agents' idiosyncratic employment status. The unemployment risk is thus entirely uninsurable. Second, agents face an exogenous debt limit preventing them from issuing debt securities in both aggregate states. Third, no security offers a payoff contingent to the aggregate state of the economy. We thus only study the yields of bonds, whose terminal payoff is certain. These properties are the heart of a vast literature on liquidity-constrained economies ${ }^{3}$ since the seminal work of Bewley (1980).

The only assets that agents may buy and sell are riskless zero-coupon bonds. They pay off one unit of goods at maturity, and are issued by the government. The maturities of these bonds vary from 1 to $n \geq 1$, where $n$ may be arbitrarily large. A bond of maturity $k>1$ at date $t$ becomes a bond of maturity $k-1$ at date $t+1$, and eventually yields 1 at date $t+k$. The price of this bond at date $t$ is denoted $p_{t, k}\left(h^{t}\right)$. To simplify notations, we define the price of a bond of maturity 0 as its payoff: $p_{t, 0}\left(h^{t}\right)=1$.

Bond payoffs are financed by both new government bond issuances and taxes. At each date $t$, a given net quantity $A_{t, k}$ of zero coupon bonds paying one unit of good at period $t+k$ is issued by the government at price $p_{t, k}\left(h^{t}\right)$. The government repays bonds arriving at maturity at date $t$

In order to minimize tax distortions, we assume that the government uses lump-sum transfers contingent to the employment status. Unemployed agents pay no tax, while all employed agents pay the same amount $\tau^{e} .{ }^{4}$ Given that the latter are in proportion $\omega^{e}$, the government budget constraint is given by:

$$
\sum_{k=1}^{n} p_{t, k} A_{t, k}+\omega^{e} \tau_{t}^{e}=\sum_{k=1}^{n} A_{t-k, k}
$$

The aggregate supply of securities with a given maturity is composed of newly issued bonds of that maturity plus longer bonds issued earlier and becoming closer to maturity. At date $t$, a total

\footnotetext{
${ }^{2}$ This assumption appears as empirically relevant: Using US quarterly data on GNP, Hamilton (1994), chap 22, finds that $\pi^{h}+\pi^{l}=1.65$.

${ }^{3}$ See Kehoe and Levine (2001) for references on related papers.

${ }^{4}$ Introducing either proportional taxes on the labor income or lump sum taxes on the unemployed would generate additional distortions and/or redistributive effects, whose impacts are beyond the scope of this paper.
} 
quantity $B_{t, k}$ of bonds reaching maturity at date $t+k$ is available on the market, where:

$$
B_{t, k} \equiv \sum_{j=0}^{n-k} A_{t-j, k+j}
$$

For sake of conciseness, we focus on the case where the quantity bonds of a given maturity is constant (i.e., $B_{t, k}=B_{k}, \forall t \geq 0$ ), but the model can easily accommodate stochastic changes in the bond supply. Constant bond quantities per maturity is equivalent to constant issuances, i.e. $A_{t, k}=A_{k}, \forall t \geq 0$.

\section{$2.3 \quad$ Firms}

There is a large number of perfectly competitive firms, which produce a single final good using only labor with a constant return-to-scale technology. The labor productivity, $z_{t}$, depends on the aggregate state of the economy. The productivity levels in state $h$ and $l$ are respectively $z^{h}$ and $z^{l}$, where $z^{h} \geq 1 \geq z^{l}>0$. The firms' profit maximization under perfect competition implies that the real wage $w_{t}$ is equal to the marginal product of labor, i.e. $w_{t}=z_{t}$.

\section{4 agents}

There is a continuum of agents of mass 1. Each agent $i$ has preferences over consumption and labor. We follow Scheinkman an Weiss (1986) in assuming that intertemporal preferences are timeseparable and that the agents' instantaneous utility is $u(c)-l$, where $c$ is the consumption, $l$ is the labor supply, and $u$ is a $C^{2}$ function satisfying $u^{\prime}()>$.0 , and $u^{\prime \prime}()<$.0 . The marginal disutility of labor is constant and normalized to 1 . All agents discount their instantaneous utility with the same factor $\beta \in(0,1)$.

In period $t$, each agent $i$ consumes an amount $c_{t}^{i}$, supplies the labor quantity $l_{t}^{i}$, and demands the quantity $b_{t, k}^{i}$ of bonds with maturity $k$. The agent also pays a lump-sum tax $\tau_{t}\left(e_{t}^{i}\right)$, which is contingent to his employment status. Employed agents choose their labor supply and earn a hourly wage equal to $w_{t}$. Unemployed agents earn no labor income, but a constant amount of home production $\delta \geq 0$. Their labor supply is by definition equal to 0 . We note $b_{-1, k}^{i}$ the quantity of $k$-period bonds that the agent $i$ holds at the beginning of period 0. Specific assumptions about initial bond holdings will be made in section 4 in order to simplify the transitional dynamics of the model.

The agent $i$ 's problem consists in choosing the following sequences of functions:

$$
\left.\begin{array}{c}
c_{t}^{i}: H^{t} \times E^{t} \rightarrow R_{+} \\
l_{t}^{i}: H^{t} \times E^{t} \rightarrow R_{+} \\
b_{t, k}^{i}: H^{t} \times E^{t} \rightarrow R_{+} \quad k=1, \ldots, n
\end{array}\right\} t=0,1, \ldots
$$


which maximize the agent's intertemporal expected utility:

$$
\sum_{t=0}^{\infty} \beta^{t} \sum_{h^{t} \in H^{t}} \nu_{t}\left(h^{t}\right) \sum_{e^{i, t} \in E^{t}} \mu_{t}^{i}\left(e^{i, t}\right)\left(u\left(c_{t}^{i}\left(h^{t}, e^{i, t}\right)\right)-l_{t}^{i}\left(h^{t}, e^{i, t}\right)\right),
$$

subject to the following constraints:

$$
\begin{aligned}
c_{t}^{i}\left(h^{t}, e^{i, t}\right)+\tau_{t}\left(e_{t}^{i}\right)+\sum_{k=1}^{n} p_{t, k}\left(h^{t}\right) b_{t, k}^{i}\left(h^{t}, e^{i, t}\right) & =\sum_{k=1}^{n} p_{t, k-1}\left(h^{t}\right) b_{t-1, k}^{i}\left(h^{t-1}, e^{i, t-1}\right) \\
& +e_{t}^{i} z_{t} l_{t}^{i}\left(h^{t}, e^{i, t}\right)+\left(1-e_{t}^{i}\right) \delta \\
c_{t}^{i}\left(h^{t}, e^{i, t}\right), \quad l_{t}^{i}\left(h^{t}, e^{i, t}\right) & \geq 0 \\
b_{t, k}^{i}\left(h^{t}, e^{i, t}\right) & \geq 0 \\
\lim _{t \rightarrow \infty} \beta^{t} u^{\prime}\left(c_{t}\left(h^{t}, e^{i, t}\right)\right) b_{t, k}^{i}\left(h^{t}, e^{i, t}\right) & =0 \quad \text { for } k=1, \ldots, n
\end{aligned}
$$

The budget constraint (2) equalizes agents' inflows and total outflows at date $t$. The total inflows of the agent $i$ at date $t$ is the sum of the sale value of the bond portfolio on the one hand, and on the other hand, of the labor income if $e_{t}^{i}=1$, or of the home production income if $e_{t}^{i}=0$. The agent spends his current income on consumption goods and on bonds of various maturities, as well as on paying lump sum taxes. The constraint (4) indicates that agents cannot issue any debt securities. Finally, (5) is the set of transversality conditions, which always hold along the equilibrium we will be considering.

We also make the following assumption:

\section{Assumption B $1 / z^{l}<u^{\prime}(\delta)$}

This assumption implies that in equilibrium, the marginal utility of the consumption enjoyed by an unemployed agent is always higher than that the one enjoyed by an employed agent (i.e. the unemployed are always worse-off than the employed in both aggregate states). In other words, the utility gain afforded by one unit of labor paid at the lowest wage provides an upper bound for the jobless income $\delta$.

The Lagrangian function associated with the agent $i$ 's problem is as follows:

$$
\begin{array}{r}
L=\sum_{t=0}^{\infty} \beta^{t} \sum_{h^{t} \in H^{t}} \nu_{t}\left(h^{t}\right) \sum_{e^{i, t} \in E^{t}} \mu_{t}\left(e^{i, t}\right) \times\left[u\left(c_{t}^{i}\left(h^{t}, e^{i, t}\right)\right)-l_{t}^{i}\left(h^{t}, e^{i, t}\right)+\sum_{k=1}^{n} \varphi_{t, k}^{i}\left(h^{t}, e^{i, t}\right) b_{t, k}^{i}\left(h^{t}, e^{i, t}\right)\right. \\
+\eta_{t}^{i}\left(h^{t}, e^{i, t}\right)\left(e_{t}^{i} z_{t} l_{t}^{i}\left(h^{t}, e^{i, t}\right)+\left(1-e_{t}^{i}\right) \delta-\tau_{t}\left(e_{t}^{i}\right)+\sum_{k=1}^{n} p_{t, k-1}\left(h^{t}\right) b_{t-1, k}^{i}\left(h^{t-1}, e^{i, t-1}\right)\right. \\
\left.\left.-c_{t}^{i}\left(h^{t}, e^{i, t}\right)-\sum_{k=1}^{n} p_{t, k}\left(h^{t}\right) b_{t, k}^{i}\left(h^{t}, e^{i, t}\right)\right)\right]
\end{array}
$$

The Lagrange multipliers $\eta_{t}^{i}$ and $\varphi_{t, k}^{i}$ are positive functions defined over $H^{t} \times E^{t}$, and are associated with the budget constraint (2) and the borrowing constraint (4), respectively. (We check 
below that the nonnegativity constraints (3) for $c_{t}^{i}$ and $l_{t}^{i}$ are always satisfied in the equilibrium we consider). From the Kuhn and Tucker theorem, the optimality conditions are, for $t=0,1, \ldots$ and for all $\left(h^{t}, e^{i, t}\right) \in H^{t} \times E^{t}$ :

$$
\begin{aligned}
& u^{\prime}\left(c_{t}^{i}\left(h^{t}, e^{i, t}\right)\right)=\eta_{t}^{i}\left(h^{t}, e^{i, t}\right) \\
& \left\{\begin{aligned}
\eta_{t}^{i}\left(h^{t}, e^{i, t}\right) & =1 / z_{t} & & \text { if } \quad e_{t}^{i}=1 \\
l_{t}^{i}\left(h^{t}, e^{i, t}\right) & =0 & & \text { if } \quad e_{t}^{i}=0
\end{aligned}\right. \\
& \eta_{t}^{i}\left(h^{t}, e^{i, t}\right) p_{t, k}\left(h^{t}\right)=\beta \sum_{h^{t+1} \succeq h^{t}} \nu_{t+1}\left(h^{t+1}\right) \sum_{e^{i, t+1} \succeq e^{i, t}} \mu_{t+1}^{i}\left(e^{i, t+1}\right) \eta_{t+1}^{i}\left(h^{t+1}, e^{i, t+1}\right) p_{t+1, k-1}\left(h^{t+1}\right) \\
& +\varphi_{t, k}^{i}\left(h^{t}, e^{i, t}\right) \quad \text { for } k=1, \ldots, n \\
& \left\{\begin{array}{ll}
\text { either } & \varphi_{t, k}^{i}\left(h^{t}, e^{i, t}\right)>0 \text { and } b_{t, k}^{i}\left(h^{t}, e^{i, t}\right)=0 \\
\text { or } & \varphi_{t, k}^{i}\left(h^{t}, e^{i, t}\right)=0 \text { and } b_{t, k}^{i}\left(h^{t}, e^{i, t}\right)>0
\end{array} \quad \text { for } \quad k=1, \ldots, n\right.
\end{aligned}
$$

The equation (6) defines the agent $i$ 's marginal utility of consumption, while the equality (7) expresses his optimal labor supply. When the agent works $\left(e_{t}^{i}=1\right)$, he equalizes the marginal gain in consumption and the marginal pain of labor (i.e., $\left.1 / u^{\prime}\left(c_{t}^{i}\left(h^{t}, e^{i, t}\right)\right)=1 / z_{t}\right)$, while no labor supply is provided when the agent is unemployed $\left(e_{t}^{i}=0\right)$. The equation (8) is the intertemporal optimality condition, which can also be written more compactly as:

$$
u^{\prime}\left(c_{t}^{i}\left(h^{t}, e^{i, t}\right)\right) p_{t, k}\left(h^{t}\right)=\beta E_{t}\left[u^{\prime}\left(c_{t+1}^{i}\left(h^{t+1}, e^{i, t}\right)\right) p_{t+1, k-1}\left(h^{t+1}\right)\right]+\varphi_{t, k}^{i}\left(h^{t}, e^{i, t}\right),
$$

where $E_{t}[\cdot]$ is the expectation over aggregate and idiosyncratic states, conditional on the information available at date $t$ (i.e. $h^{t}$ and $e^{i, t}$ here). The Euler equation (10) equalizes the marginal cost of acquiring one unit of bonds of each maturity today with the marginal gain associated with its payoff tomorrow. When the shadow cost of the borrowing constraints is positive, meaning that the constraint is actually binding $\left(\varphi_{t, k}^{i}\left(h^{t}, e^{i, t}\right)>0\right)$, then the agent $i$ would like to increase his expected utility by issuing $k$-period bonds (but he is prevented from doing so by assumption). The equation (9) finally summarizes the relationship between the shadow-cost $\varphi_{t, k}$ and the binding borrowing constraint.

\subsection{Market clearing}

The bond markets clear at date $t$ when the bond supply for each maturity equates the bond demand for the same maturity, i.e.:

$$
\int_{0}^{1} b_{t, k}^{i}\left(h^{t}, e^{i, t}\right) d i=B_{k}, \forall k=1, \ldots, n
$$

By the Walras Law, the good market clears when all the bond markets clear. 


\section{Equilibrium with full asset liquidation}

One implication of our particular market structure is that available assets play the role of buffer stocks, since they allow agents to partially offset the lack of full credit and insurance markets. However, many models of this class imply a smooth portfolio rebalancing in equilibrium: High income agents gradually build up their asset wealth, while low income ones decumulate assets at a sufficiently slow pace not to ever actually hit the borrowing constraint (e.g. Scheinkman and Weiss (1986), or Aiyagari (1994)). Since we focus on the implications of the liquidation risk for the bond pricing, we construct our equilibrium in such a way that agents indeed liquidate assets when a bad idiosyncratic income shock hurts (i.e., $b_{t, k}^{i}\left(h^{t}, e^{i, t}\right)=0$ for $k=1, \ldots, n$ if $e_{t}^{i}=0$ ). All low income agents face therefore a binding credit constraint, which cannot be offset through bond liquidation.

Incidentally, this full liquidation of bond holdings drastically reduces the number of agent types in the economy, thereby allowing us to study bond pricing analytically for an arbitrarily large number of maturities.

Our equilibrium is obtained by construction: We first conjecture, and then derive a sufficient condition for, the existence of an equilibrium along which employed agents are never borrowingconstrained (i.e. they are willing to save and thus hold a positive quantity of bonds at the end of the current period), while unemployed ones always hit the borrowing constraint (i.e. they would like to borrow, rather than hold positive bond holdings, at the end of the current period). From (9), this joint conjecture can formally be written as:

$$
\left\{\begin{array}{l}
\text { If } e_{t}^{i}=1 \text { then } \varphi_{t, k}^{i}\left(h^{t}, e^{i, t}\right)=0 \\
\text { If } e_{t}^{i}=0 \text { then } \varphi_{t, k}^{i}\left(h^{t}, e^{i, t}\right)>0
\end{array} \quad \text { for all } k=1, \ldots, n\right.
$$

\subsection{Equilibrium consumption levels}

Let us first consider the consumption of an unemployed agent in period $t$. If the agent was employed in the previous period, then from the budget constraint (2) and conjecture (12), he earns the home production $\delta$ and the liquidation value of his portfolio. He consumes his complete revenue, because he is borrowing constrained. His consumption expresses therefore as:

$$
c_{t}^{i}=\sum_{k=1}^{n} p_{t, k-1} b_{t-1, k}^{i}+\delta(>0)
$$

The consumption of unemployed agents, who were already unemployed in the previous period, is identical across analogous agents. They earn the home production $\delta$ and cannot raise consumption through borrowing. Their current consumption, denoted $c_{t}^{u u}$, is thus:

$$
c_{t}^{u u}=\delta(>0)
$$

Let us now turn to employed agents. From their intratemporal optimality conditions (6) and (7), 
their consumption level, denoted $c_{t}^{e}$, is identical across employed agents. Employed agents equalize the marginal utility of consumption to the marginal pain of labor. The constant disutility of labor pins down the consumption, which depends only on preference parameters and the aggregate shock:

$$
c^{e}=u^{\prime-1}\left(1 / z_{t}\right)(>0)
$$

If this agent is employed in the next period, which occurs with the probability $\alpha$, then $\eta_{t+1}^{i}=1$ (see Eq. (7)). If the agent falls into unemployment in the next period, then from (6) $\eta_{t+1}^{i}=u^{\prime}\left(c_{t+1}^{i}\right)$, where by construction $c_{t+1}^{i}$ is given by the equality (13). From the first order conditions (6), (7), and (10) of the agent program and the equation (12), Euler equations for employed agents is given by $(k=1, \ldots, n)$ :

$$
\frac{p_{t, k}}{z_{t}}=\alpha \beta E_{t}\left[\frac{p_{t+1, k-1}}{z_{t+1}}\right]+(1-\alpha) \beta E_{t}\left[u^{\prime}\left(\sum_{j=1}^{n} p_{t+1, j-1} b_{t, j}^{i}+\delta\right) p_{t+1, k-1}\right]
$$

We restrict our attention to the symmetric equilibrium, where all employed agents hold the same quantities of bonds for maturities $k=1, \ldots, n$. These quantities are only determined by preference parameters and aggregate variables. Hence, we denote $b_{t, k}^{e}$ the quantity of $k$-period bond held by employed agents at date $t$. The consumption level $c_{t}^{e u}$ is now identical across agents, who are unemployed at date $t$ and were employed at date $t-1$. The equation (13) becomes therefore:

$$
c_{t}^{e u}=\sum_{k=1}^{n} p_{t, k-1} b_{t-1, k}^{e}+\delta
$$

\subsection{Market clearing}

Because all employed agents hold the same quantity of securities for each maturity, and unemployed agents do not hold any asset, the bond market equilibrium (11) is simply:

$$
\omega^{e} b_{t, k}^{e}=B_{k}, \forall k=1, \ldots, n
$$

where $\omega^{e}$ is the share of employed agents in the population given by (1).

\subsection{Pricing equations}

Since all employed agents hold the same quantity of securities, we are able to derive the simple Euler pricing equations, which are the central equations of this paper. Using the Euler equation (16) and the market equilibria (18), one obtains, for all $t \geq 0$ and $k \in\{1, \ldots, n\}$ :

$$
\frac{p_{t, k}}{z_{t}}=\alpha \beta E_{t}\left[\frac{p_{t+1, k-1}}{z_{t+1}}\right]+(1-\alpha) \beta E_{t}\left[p_{t+1, k-1} u^{\prime}\left(\delta+\frac{1}{\omega^{e}} \sum_{j=1}^{n} p_{t+1, j-1} B_{j}\right)\right]
$$


The previous equations pin down the price of any bond as a function of the current and next aggregate states, of all future prices, and of the bond supply. Each of these equations express the price of a $k$-period bond as the sum of two distinct terms, depending on the employment status of the agent in the next period. If the agent stays employed (which occurs with probability $\alpha$ ), then the labor supply freely adjusts to equalize the marginal utility of consumption with the inverse of the real wage $1 / z_{t+1}$. This term is the only one that would prevail if markets were complete and if agents were fully able to smooth out idiosyncratic income shocks. The second term in the right hand side of the equation (19) reflects the liquidation risk, associated with the possibility that the agent could be hurt by an unfavorable change in employment status. Bond quantities directly affect prices through their effect on the value of the liquidated portfolio, which in turn feeds back into current equilibrium prices.

\subsection{Conjectured asset price structure}

We focus on the equilibrium where bond prices depend only on the realization of aggregate shocks. Following the literature on asset pricing with a finite state space (Mehra and Prescott (1985) among others), we conjecture the following expression for bond prices:

$$
\forall t \geq 0, \forall k \in\{1, \ldots, n\}, \forall s \in\{h, l\} \quad p_{t, k}^{s}=C_{k}^{s} z^{s}
$$

where the $C_{k}^{s} \mathrm{~S}$ are constant. This conjectured price structure exhibits a form of stationarity, as bond prices depend only on their maturity and the current aggregate state. In consequence, there are two yield curves, one for each value of the aggregate state. Our existence proof will thus consist in showing that such a stationary equilibrium exists.

The pricing equations (19) expressed in both states $h$ and $l$ provide the expressions for $C_{k}^{h}$ and $C_{k}^{l}$ for $k \geq 1$. We introduce the following notations:

$$
\begin{gathered}
{\left[\begin{array}{c}
C_{0}^{h} \\
C_{0}^{l}
\end{array}\right] \equiv\left[\begin{array}{c}
1 / z^{h} \\
1 / z^{l}
\end{array}\right]} \\
\left\{\begin{array}{c}
u^{\prime h} \equiv u^{\prime}\left(\delta+\sum_{i=0}^{n-1} C_{i}^{h} z^{h} B_{i+1} / \omega^{e}\right) \\
u^{\prime l} \equiv u^{\prime}\left(\delta+\sum_{i=0}^{n-1} C_{i}^{l} z^{l} B_{i+1} / \omega^{e}\right)
\end{array}\right.
\end{gathered}
$$

The price structure (19) can then be written compactly in a recursive form as follows, for $k=1, \ldots, n$ :

$$
\left[\begin{array}{c}
C_{k}^{h} \\
C_{k}^{l}
\end{array}\right]=\beta T \cdot\left[\begin{array}{cc}
\alpha+(1-\alpha) z^{h} u^{\prime h} & 0 \\
0 & \alpha+(1-\alpha) z^{l} u^{\prime l}
\end{array}\right] \cdot\left[\begin{array}{c}
C_{k-1}^{h} \\
C_{k-1}^{l}
\end{array}\right]
$$

This system provides $2 \times n$ equations that determine the $2 \times n$ coefficients $\left\{C_{k}^{h}, C_{k}^{l}\right\}_{k=1, \ldots, n}$. This system is not linear, because the whole price structure appears in each coefficient $u^{\prime h}$ and $u^{\prime l}$. 
The yield to maturity of a bond with maturity $k=1, \ldots, n$ in state $s=h, l$ and in period $t \geq 0$ is defined by the usual expression $r_{t, k}^{s}=-k^{-1} \ln p_{t, k}^{s}$. Interest rates are supposed to be continuously compounded. The average yield curve is the sum of yield curves in states $h$ and $l$ weighted by the average frequency of aggregate state $h$ and $l$ (given by the matrix $T$ ). The average yield $r_{t, k}$ of maturity $k$ at date $t$ is thus:

$$
r_{t, k}=\frac{1-\pi^{l}}{2-\pi^{l}-\pi^{h}} r_{t, k}^{h}+\frac{1-\pi^{h}}{2-\pi^{l}-\pi^{h}} r_{t, k}^{l}
$$

This simple recursive structure is now used first to prove the existence of a stationary equilibrium, and then to analyze how the equilibrium yield curve is affected by the bond supply.

\section{Existence of the equilibrium}

We begin with imposing some general conditions ensuring that our equilibrium with limited agents' heterogeneity exists. We then establish the existence of an equilibrium with an arbitrarily large number of bond maturities. This is done first by deriving the equilibrium yield curve under aggregate certainty and zero net supply for all maturities. We show then, that the yield curve is continuous with respect to both the introduction of small aggregate uncertainty and that of small and positive supply of bonds. This allows us to extend our existence result to a more general case.

\subsection{General conditions for the equilibrium to exist}

The stationary distribution with four agents' types is constructed under the assumption that unemployed agents are always borrowing-constrained, while no employed agent is. We now derive the conditions under which this is indeed the case.

\subsubsection{Condition on agents' initial wealth}

In order to avoid the complications related to the transitional adjustment of agents' wealth levels towards the steady state, we assume that at the beginning of period 0 , employed agents have a probability $\alpha$ to hold an initial quantity of bonds $b_{-1, k}^{e e}=B_{k} / \omega^{e}$, and a probability $1-\alpha$ to hold $b_{-1, k}^{u e}=0$. Unemployed agents have a probability $\rho$ to hold $b_{-1, k}^{u u}=0$, and a probability $1-\rho$ to hold $b_{-1, k}^{e u}=B_{k} / \omega^{e}$. In consequence, from an ex ante point of view, agents have a probability $\alpha \omega^{e}$ to be employed with positive bond holdings, and a probability $(1-\rho) \omega^{u}$ to be unemployed with positive bond holdings. The initial cross distribution of labor status and bond holdings is thus identical to the stationary one.

\subsubsection{Condition on parameter values}

agents who are unemployed at both dates $t-1$ and $t$ consume the amount $c_{t+1}^{u u}=\delta$. If they become employed in the next period, which occurs with probability $1-\rho$, then $\eta_{t+1}^{i}=1$ (see 
Eq. (7)). Moreover, if they remain unemployed, which occurs with probability $\rho$, then from (6) $\eta_{t+1}^{i}=u^{\prime}\left(c_{t+1}^{u u}\right)=u^{\prime}(\delta)$. Equations (6), (7), and (10) imply that the condition (12), which precisely states that these agents are constrained, is equivalent to:

$$
\forall k=1, \ldots, n, \quad p_{t, k} u^{\prime}(\delta)>\beta(1-\rho) E_{t}\left[\frac{p_{t+1, k-1}}{z_{t+1}}\right]+\beta \rho u^{\prime}(\delta) E_{t}\left[p_{t+1, k-1} u^{\prime}(\delta)\right]
$$

agents who were employed at date $t-1$ and become unemployed at date $t$ consume their home production $\delta$ as well as the liquidation value of their bond portfolio. From the equation (12) again, these agents face binding borrowing constraints if and only if:

$$
\forall k \quad p_{t, k} u^{\prime}\left(\delta+\sum_{j=1}^{n} p_{t, j-1} b_{t-1, j}^{e}\right)>\beta(1-\rho) E_{t}\left[\frac{p_{t+1, k-1}}{z_{t+1}}\right]+\beta \rho u^{\prime}(\delta) E_{t}\left[p_{t+1, k-1} u^{\prime}(\delta)\right]
$$

Note that the inequality (25) holds; as soon as (26) does. We thus only need to check that the inequality (26) holds, i.e. that agents just falling into unemployment become constrained and liquidate their bond portfolio. This in turn implies that unemployed agents who were already so, also face binding borrowing constraint.

\subsection{Equilibrium existence with zero net supply and no aggregate shock}

If assets are in zero net supply, then $\sum_{j=1}^{n} p_{t, j-1} b_{t-1, j}^{e}=0$. With no aggregate uncertainty, $z_{t}=z$ $\forall t$, and the equation (20) becomes $p_{t, k}=C_{k} z$ (i.e. the $C_{k}^{s}$ s only depend on the bond maturity). Then, substituting (20) into (19) and (26) and rearranging, we obtain that the inequality (26) is equivalent to:

$$
\left(\alpha+(1-\alpha) u^{\prime}(\delta)\right) u^{\prime}(\delta)>(1-\rho)+\rho u^{\prime}(\delta)
$$

Since $u^{\prime}(\delta)>1$ (from assumption $\mathbf{B}$ ), this condition is satisfied as soon as $\alpha<1^{5}$. As long as credit constraints are binding, our equilibrium exists in an economy without aggregate risk and with a zero net supply.

\subsection{Continuity of the yield curve as a function of bond supply and shocks}

The following proposition summarizes the regularity property of the yield curve, which will be used extensively below. We introduce the following notations: $B$ is the (column) vector of bond quantities for the $n$ maturities: $B=\left[B_{1} \ldots B_{n}\right]^{\top}, Z$ the vector of wages (or equivalently productivities) $Z=\left[\begin{array}{ll}z^{l} & z^{h}\end{array}\right]^{\top}$ and $C$ is the vector of coefficients for both states $h$ and $l$ and the $n$ maturities:

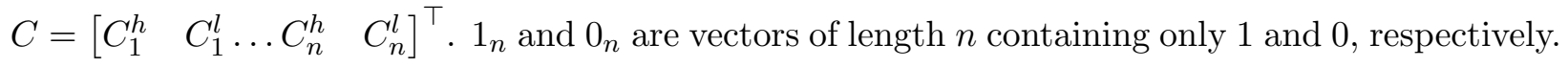

Proposition 1 (Regularity of the yield curve) If $B$ is in the neighborhood of $0_{n}$ and $Z$ in the neighborhood of $1_{2}$, then $C$ is a $\mathcal{C}^{1}$ function of $B$ and of $Z$. The equilibrium exists; as long as both the aggregate uncertainty and the bond supply are small.

\footnotetext{
${ }^{5}$ The RHS reaches its maximum $u^{\prime}(\delta)$ when $\rho=1$ and when $\alpha<1$, we have $\left(\alpha+(1-\alpha) u^{\prime}(\delta)\right) u^{\prime}(\delta)>u^{\prime}(\delta)$.
} 
All proofs are gathered in the Appendix. The proposition 1 essentially states that, starting from a no uncertainty-zero net supply situation, a gradual increases in the aggregate risk or in the bond supply does not cause the yield curve to jump.

\subsection{Equilibrium existence in the general case}

The system (23) with initial conditions (21) defines the vector of price constants $C$ as a continuous function of bond volumes $B$ and of real wages $Z$, when $\left[B^{\top} Z^{\top}\right]$ is in a neighborhood $V_{1}$ of $\left[\begin{array}{ll}0_{n}^{\top} & 1_{2}^{\top}\end{array}\right]$. Moreover, if $\left[B^{\top} Z^{\top}\right]=\left[\begin{array}{ll}0_{n}^{\top} & 1_{2}^{\top}\end{array}\right]$, the equilibrium vector $C$ satisfies conditions (26). By continuity, there exists a neighborhood $V_{2} \subset V_{1}$ of $\left[\begin{array}{ll}0_{n}^{\top} & 1_{2}^{\top}\end{array}\right]$, such that conditions (26) is fulfilled if $\left[B^{\top} Z^{\top}\right] \in V_{2}$.

If the supply of bonds of any maturities remains small, and if the variance of the aggregate shock is low enough (the process $z$ remains around the mean 1 ), then the equilibrium with four agents' types exists.

\section{$5 \quad$ Volume effects on the yield curve}

We may now state our main results regarding the impact of bond volumes on the yield curve. The following lemma characterizes the ranking of yield curves according to the aggregate state. All results are obtained for $\alpha<1$ and $B$ small enough for the equilibrium to exist.

Lemma 1 (Ranking of yield curves) The yield curve in the good aggregate state lies strictly below the one in the bad aggregate state: $r_{k}^{h}<r_{k}^{l} \quad k=1, \ldots, n$. Yields in both aggregate states converge to a common limit: $\lim _{k \rightarrow \infty} r_{k}^{l}=\lim _{k \rightarrow \infty} r_{k}^{h}=r^{\lim }$.

Note that this statement is not related to the presence of borrowing constraints per se. In the good state, employed agents choose a higher level of savings than in the bad state (where their labor income is lower), leading to higher bond prices for all maturities in the good state than in the bad state.

We define the slope of the yield curve $\Delta$ as the difference between the long run yield $r^{\text {lim (see }}$ lemma 2) and the average short yield, $r_{1}$ given by (24): $\Delta=r^{\lim }-r_{1}$. The following proposition summarizes the effect of a variation in the net supply of bonds on the level and the slope of the yield curve.

Proposition 2 (Impact of bond volumes on the shape of the curve) 1) Raising the net sup-

ply of bonds of any maturity increases the level of the yield curve: $\frac{\partial p_{k}^{s}}{\partial B_{i}}<0$ for $i, k=1, \ldots, n$ et $s=h, l$.

Moreover if $\alpha$ is close to 1 , then:

2) Raising the net supply of bonds of any maturity increases the slope of the yield curve : $\frac{\partial \Delta}{\partial B_{i}}>0$ for $i=1, \ldots, n$. 
The first statement in the proposition 2 establishes that a larger bond supply of any maturity decreases the prices bonds of all maturities (including the price of arbitrarily long bonds) in both aggregate states, and thus shifts the yield curve upward. This effect stems from the specific liquidity role played by bonds in this economy. Employed agents, who earn a high labor market income, want to self-insure themselves against the risk of falling into unemployment. Available bonds of any maturity may serve this purpose. A small supply of bonds makes such liquidity devices highly valuable and thus yields a high price, relative to a situation where bonds are abundant. Conversely, an increase in the total liquidity, through for example a larger bond supply (whatever the maturity), lowers the price of all bonds. Put it shortly, incomplete markets coupled with borrowing constraints make the aggregate bond demand downward-sloping (notice that when $\alpha=1$ no agent is ever constrained and this effect of bond supply on equilibrium prices vanishes) ${ }^{6}$.

The second statement in proposition 2 bears upon the variations in relative bond prices induced by a variation in the total supply of bonds. It is noteworthy that $\alpha$ should be close to $1^{7}$. The increase in the supply of bonds raises the slope of the yield curve because of two effects. First, note that agents care about the expected liquidation value of their portfolio in the next period, which is $\sum_{j=1}^{n} p_{t+1, j-1}\left(B_{j} / \omega^{e}\right)$. For simplification purpose, we assume that the volume of bonds with a maturity $k>1$ increases, whereas all other volumes are null. In this case, the variance of the portfolio is $\operatorname{var}\left[p_{t+1, k-1}\right]\left(B_{k} / \omega^{e}\right)^{2}$, which increases with $B_{k}$ : The liquidation value of the portfolio becomes more volatile, when the bond supply increases, whatever its maturity. However, longterm bonds are more likely to be liquidated before maturity. When the volatility of the portfolio increases, this increases the risk of holding long term bonds, which commands therefore a larger risk premium than for shorter ones. Second, when the volumes of bonds increase, agents are better able to self-insure themselves. In consequence, their demand for self-insurance decreases. As bonds of various maturities are imperfect substitutes of each other, because their probability to be sold before maturity differs, the relative demand for longer bonds decreases compared to shorter ones. Here again, both effects of the total supply of bonds on the slope vanishes, when the idiosyncratic uncertainty shuts down (i.e. when $\alpha=1$ ).

\section{Welfare}

In our model, the net bond supply is arbitrarily set. Taxes simply adjust, so as to satisfy the government budget constraint at all times. The equilibrium is then indexed by the quantity of bonds available in the economy. This model is simple enough to allow us to rank equilibria according to

\footnotetext{
${ }^{6}$ The positive effect of bond volumes on interest rates have been underlined in various empirical works (Duffee (1996), Fleming (2002) among others). Other empirical studies, however, have found the opposite effect (see Amihud and Mendelson (1991), for example). Jegadeesh (2002) conjectures that the negative effect of volumes on prices may occur in markets, which lack depth. In such markets, a larger bond supply may increase trading volumes, thereby reducing trading frictions and raising prices.

${ }^{7}$ This case where $\alpha$ is close to one seems to be the most relevant one empirically. According to Nickell, Nunziata, Ochel, and Quintini (2001), annual job-loss probabilities (1- $\alpha$ in our model) are no higher than 0.04 in most OECD countries.
} 
a Pareto criterion.

Proposition 3 (Pareto ranking of equilibria) Without aggregate shock, a larger bond supply:

1. always increases, in a Pareto sense, ex ante welfare,

2. always increases the welfare of ee and eu agents, but increases the welfare of ue and uu agents if and only if $\beta>[\alpha+(1-\alpha) u]^{-1}$.

If from an ex ante point of view, when agents ignore their types, a larger bond supply is Pareto improving, this improvement is not homogeneous across types. First, instantaneous utilities of agents $e e$ and $u u$ are not affected. It is neutral for $u u$ since they only earn a constant income $\delta$. For ee agents, the increase in taxation (which finances a larger bond supply) is fully offset by the higher value of the portfolio they sell. On the opposite, types ue do not have any asset to sell (they were unemployed and thus credit constrained at the preceding period) and only sustain the tax increase, which make them work more. Finally, agents $e u$ are unemployed, but do not pay any tax: They therefore benefit from a higher value of their bond portfolio. Instantaneously, a larger bond supply is a redistribution from ue (who work but do not have any security for sale) to eu (who are unemployed, but liquidate a bond portfolio). Since the marginal gain of eu is larger than the marginal loss of $u e$, and since both types are equally probable, the first part of the proposition is straightforward: ex ante, a larger bond supply is always Pareto improving.

The expected welfare comparison from date 0 point of view, when agents know their type, is less direct. The expected utility for each type balances today's impact and tomorrow's one. It is noteworthy that the situation of the agent ee (resp. uu) is analogous to the one of $e u$ (resp. ue), since he is currently not impacted with bond supply. On the one hand, the ue agent's utility is positively impacted by a larger bond supply, only if his current loss is offset by the gain of becoming possibly tomorrow eu: If the agent is patient enough, the increase in bond supply will be welfare improving. On the other hand, the today's gain of the agent $e u$ is mitigated by the probability of becoming tomorrow ue and therefore by the fact from possibly suffering from a larger bond supply. However, instantaneous utilities imply that this possible loss cannot be large enough to offset the today's certain gain. Finally, eu agents, as ee ones, always benefit from an increase in bond supply, whereas ue and thus uu may suffer from it, if they are not patient enough.

\section{Concluding remarks}

This paper has analyzed the yield curve implications of a simple dynamic general equilibrium model with incomplete markets, and where agents face both idiosyncratic and aggregate shocks. The model was constructed under the assumption that assets are fully liquidated following an adverse idiosyncratic income shock. This allowed us to derive analytical expressions for bond prices at any maturity, and to study how changes in bond issuances could alter the level and slope of the entire yield curve as well as the welfare of (heterogeneous) agents. 
Other analytical properties of the yield curve can be derived within this framework, and are available in an extended version of this paper. First, market incompleteness contributes to the rejection of the expectation hypothesis. Second, when markets are incomplete, bond supply affects the variance of the yield curve. These results, which stem from the interaction between aggregate and idiosyncratic risks, find some empirical support ${ }^{8}$. Finally, this simple model could be extended to study the economic determinants of the yield curve under incomplete markets.

\footnotetext{
${ }^{8}$ The expectation hypothesis states that the one period holding return is identical whatever the bond maturity. It is a natural outcome of yield curve models with complete markets. Data on nominal (Campbell and Shiller (1991)) and real (Seppälä (2004)) rates reject this hypothesis.
} 


\section{References}

AiyagaRI, R. S. (1994): "Uninsured Idiosyncratic Risk and Aggregate Saving," The Quarterly Journal of Economics, 109(3), 659-684.

Aminud, Y., And H. Mendelson (1991): "Liquidity, maturity, and the yields on U.S. Treasury securities," Journal of Finance, 46, 1411-1425.

Bewley, T. F. (1980): "The Optimum Quantity of Money," in Models of Monetary Economies, ed. by J. Kareken, and N. Wallace, pp. 169-210. Federal Reserve Bank of Minneapolis.

- (1983): "A difficulty with the Optimum Quantity of Money," Econometrica, 54, 1485-1504.

Campbell, J. Y., And R. J. Shiller (1991): "Yield Spreads and Interest Rate Movements: A Bird's Eye View," The Review of Economic Studies, 58, 495-514.

Constantinides, G. M., and D. Duffie (1996): "Asset Pricing with Heterogeneous Consumers," Journal of Political Economy, 104(2), 219-240.

Cox, J. C., J. E. Ingersoll, And S. A. Ross (1985): "A Theory of the Term Structure of Interest Rates," Econometrica, 53, 385-409.

Duffee, G. (1996): "Idiosyncratic Variation of Treasury Bill Yields," Journal of Finance, 51, $527-552$.

Fleming, M. (2002): "Are Larger Treasury Issues More Liquid? Evidence from Bill Reopenings.," Journal of Money, Credit and Banking, 34(3), 707-735.

Hamilton, J. D. (1994): Time Series Analysis. Princeton University Press.

Huggett, M. (1993): "The risk free rate in Heterogeneous Agent Incomplete Insurance Economies," Journal of Economic Dynamics and Control, 17, 953-969.

Jegadeesh, N. (2002): "Comment of"Are Larger Treasury Issues More Liquid? Evidence from Bill Reopenings."," Journal of Money, Credit and Banking, 34(3), 736-739.

Kehoe, T. J., And D. K. Levine (2001): "Liquidity Constrained Markets versus Debt Constrained Markets ," Econometrica, 69(3), 575-578.

Krusell, P., And A. A. Smith (1997): "Income and Wealth Heterogeneity, Portfolio Choice and Equilibrium Asset Returns," Macroeconomic Dynamics, 1(2), 387-422.

Mehra, R., and E. C. Prescott (1985): "The Equity Premium: A Puzzle," Journal of Monetary Economics, 15(2), 145-161.

Nickell, S. J., L. Nunziata, W. Ochel, and G. Quintini (2001): "The Beveridge Curve, Unemployment and Wages in the OECD from the 1960s to the 1990s," CEP Discussion Papers 0502, Centre for Economic Performance, LSE.

Scheinkman, J., And L. Weiss (1986): "Borrowing Constraints and Aggregate Economic Activity," Econometrica, 54(1), 23-45.

SEPp ÄLÄ, J. (2004): "The Term Structure of Real Interest Rates: Theory and Evidence from UK Index-Linked Bonds," Journal of Monetary Economics, 51, 1509-1549. 


\section{A Proof of proposition 1}

We prove that $C_{k}^{s}$ are $\mathcal{C}^{1}$ functions of $B_{i}$ and $z^{h}, z^{l}$ for $s=h, l$ and $k, i=1, \ldots, n$. We define the following matrices $\left(u^{\prime l}\right.$ and $u^{\prime h}$ are defined in (22)):

$$
\begin{aligned}
& C=\left[\begin{array}{lllllll}
C_{n}^{h} & C_{n}^{l} & \ldots & C_{1}^{h} & C_{1}^{l} & C_{0}^{h} & C_{0}^{l}
\end{array}\right]^{\top} \\
& X=\left[\begin{array}{lll}
z^{h} & z^{l} & B^{\top}
\end{array}\right] \text { with } B=\left[\begin{array}{lll}
B_{n} & \ldots & B_{1}
\end{array}\right]^{\top} \\
& M(C, X)=\beta\left[\begin{array}{cc}
\pi^{h}\left(\alpha+(1-\alpha) z^{h} u^{\prime h}\right) & \left(1-\pi^{h}\right)\left(\alpha+(1-\alpha) z^{l} u^{\prime l}\right) \\
\left(1-\pi^{l}\right)\left(\alpha+(1-\alpha) z^{h} u^{\prime h}\right) & \pi^{l}\left(\alpha+(1-\alpha) z^{l} u^{\prime l}\right)
\end{array}\right]
\end{aligned}
$$

The price structure (23) expresses using preceding notations as $\left(0_{m \times n}\right.$ is the $m \times n$ null matrix; if $m=0$ or $n=0$, then the matrix has no dimension):

$$
f(C, X) \equiv C-\left[\begin{array}{ccccc}
0_{2 \times 2} & M(C, X) & 0_{2 \times 2} & \ldots & 0_{2 \times 2} \\
\vdots & \ddots & \ddots & & \vdots \\
\vdots & & \ddots & & M(C, X) \\
0_{2 \times 2} & & \cdots & & 0_{2 \times 2}
\end{array}\right] C-\left[\begin{array}{c}
0 \\
\vdots \\
0 \\
1 / z^{h} \\
1 / z^{l}
\end{array}\right]=0_{(2 n+2) \times 1}
$$

Since $u^{\prime}$ is $\mathcal{C}^{1}$ on $\mathbb{R}, M$ and $f$ are also $\mathcal{C}^{1}$ in $(C, X)$. Before using the implicit function theorem to show that $C$ is $\mathcal{C}^{1}$ in $(B, X)$, we prove that the Jacobian $D f_{Y}=\left(\frac{\partial f}{\partial C_{n}^{h}}, \frac{\partial f}{\partial C_{n}^{l}}, \ldots, \frac{\partial f}{\partial C_{n-i}^{h}}\right.$, $\left.\frac{\partial f}{\partial C_{n-i}^{l}}, \ldots, \frac{\partial f}{\partial C_{0}^{h}}, \frac{\partial f}{\partial C_{0}^{l}}\right)$ of $f$ relative to $C$ is invertible.

As in (22) for $u^{\prime h}$ and $u^{\prime l}$, we define $u^{\prime \prime h}$ and $u^{\prime \prime l}$ as follows:

$$
u^{\prime \prime h} \equiv u^{\prime \prime}\left(\delta+\sum_{i=0}^{n-1} C_{i}^{h} z^{h} B_{i+1} / \omega^{e}\right) \quad \text { and } \quad u^{\prime \prime l} \equiv u^{\prime \prime}\left(\delta+\sum_{i=0}^{n-1} C_{i}^{l} z^{l} B_{i+1} / \omega^{e}\right)
$$

We express partial derivatives of $f$ relative to $C_{n-i}^{s}(i=0, \ldots, n-1)$. First, derivatives with respect to $C_{n}^{h}$ and $C_{n}^{l}$ are:

$$
\frac{\partial f}{\partial C_{n}^{h}}=\left[\begin{array}{c}
1 \\
0 \\
0_{2 n \times 1}
\end{array}\right], \frac{\partial f}{\partial C_{n}^{l}}=\left[\begin{array}{c}
0 \\
1 \\
0_{2 n \times 1}
\end{array}\right]
$$

Second, derivatives relative to $C_{n-i}^{h}$ and $C_{n-i}^{l}$ for $1 \leq i \leq n$ are: 


$$
\begin{gathered}
\left.\frac{\partial f}{\partial C_{n-i}^{h}}=\left[\begin{array}{c}
0_{2(i-1) \times 1} \\
-\beta\left(\alpha+(1-\alpha) z^{h} u^{\prime h}\right) \pi^{h} \\
-\beta\left(\alpha+(1-\alpha) z^{h} u^{\prime h}\right)\left(1-\pi^{l}\right) \\
1 \\
0 \\
0_{2(n-i) \times 1}
\end{array}\right] \begin{array}{c}
-\beta(1-\alpha)\left(z^{h}\right)^{2} u^{\prime h} B_{n-i+1} / \omega^{e} \\
-R a n k 2 i+1 \\
\frac{\partial f}{\partial C_{n-i}^{l}}=\left[\begin{array}{c}
\pi^{h} C_{n-1}^{h} \\
\left(1-\pi^{l}\right) C_{n-1}^{h} \\
\vdots \\
0_{2(i-1) \times 1}^{h} C_{0}^{h} \\
\left(1-\pi^{l}\right) C_{0}^{h} \\
0_{2 \times 1}
\end{array}\right] \\
-\beta\left(\alpha+(1-\alpha) z^{l} u^{\prime l}\right)\left(1-\pi^{h}\right) \\
-\beta\left(\alpha+(1-\alpha) z^{l} u^{\prime l}\right) \pi^{l} \\
0 \\
1 \\
0_{2(n-i) \times 1}
\end{array}\right]-\beta(1-\alpha)\left(z^{l}\right)^{2} u^{\prime \prime l} B_{n-i+1} / \omega^{e}\left[\begin{array}{c} 
\\
\pi^{h} C_{n-1}^{l} \\
\left(1-\pi^{l}\right) C_{n-1}^{l} \\
\vdots \\
\pi^{h} C_{0}^{l} \\
\left(1-\pi^{l}\right) C_{0}^{l} \\
0_{2 \times 1}
\end{array}\right]
\end{gathered}
$$

The Jacobian $D f_{Y}$ expresses as the sum of an upper triangular matrix with only 1 on its diagonal and a matrix which is equal to 0 when $B=0$. Close to the zero net supply, the Jacobian is invertible and $C$ is a $\mathcal{C}^{1}$ function of $B$ and of $\left\{z^{h}, z^{l}\right\}$. QED.

\section{B Proof of lemma 1}

\section{B.1 Ranking of yield curves.}

We prove by inference in the zero net supply case $(B=0)$ that $C_{k}^{h} z^{h}>C_{k}^{l} z^{l}$ for $k=1, \ldots, n$ if $\pi^{h}+\pi^{l}>1$ using price definitions (23).

1. The result holds for $k=1$. Indeed, substituting $C_{1}^{h}$ and $C_{1}^{l}$ using (23), one finds that $C_{1}^{h} z^{h}>C_{1}^{l} z^{l}$ is equivalent to

$$
\begin{aligned}
\alpha\left(\pi^{h}-\right. & \left.\left(1-\pi^{l}\right) \frac{z^{l}}{z^{h}}+\frac{z^{h}}{z^{l}}\left(1-\pi^{h}\right)-\pi^{l}\right) \\
& >(1-\alpha) u^{\prime}(\delta)\left(\pi^{l} z^{l}+\left(1-\pi^{l}\right) z^{l}-\pi^{h} z^{h}-\left(1-\pi^{h}\right) z^{h}\right)
\end{aligned}
$$

Since $z^{h} \geq z^{l}$ and $\pi^{h}+\pi^{l}-1>0$, one can check that the left hand side is strictly positive whereas the right hand side is strictly negative.

2. For a given maturity $k \geq 2$, let us suppose that the result holds for the previous maturity: 
$C_{k-1}^{h} z^{h}>C_{k-1}^{l} z^{l}$. Proving our result $C_{k}^{h} z^{h}>C_{k}^{l} z^{l}$ is equivalent to:

$$
\begin{aligned}
& \alpha\left(\left(\pi^{h}-\left(1-\pi^{l}\right) \frac{z^{l}}{z^{h}}\right) \frac{z^{h} C_{k-1}^{h}}{z^{l} C_{k-1}^{l}}+\frac{z^{h}}{z^{l}}\left(1-\pi^{h}\right)-\pi^{l}\right) \\
& \geq(1-\alpha) u^{\prime}(\delta)\left(\pi^{l} z^{l}+\left(\left(1-\pi^{l}\right) z^{l}-\pi^{h} z^{h}\right) \frac{z^{h} C_{k-1}^{h}}{z^{l} C_{k-1}^{l}}-\left(1-\pi^{h}\right) z^{h}\right)
\end{aligned}
$$

First, consider the right hand side RHS. Since $z^{h} \geq z^{l}$ and $\pi^{h}+\pi^{l}-1>0$, we have $(1-$ $\left.\pi^{l}\right) z^{l}-\pi^{h} z^{h}<0$. By assumption $\frac{z^{h} C_{k-1}^{h}}{z^{l} C_{k-1}^{l}} \geq 1$, the RHS thus verifies:

$$
\operatorname{RHS}<(1-\alpha) u^{\prime}(\delta)\left(\pi^{l} z^{l}+\left(1-\pi^{l}\right) z^{l}-\pi^{h} z^{h}-\left(1-\pi^{h}\right) z^{h}\right)<(1-\alpha) u^{\prime}(\delta)\left(z^{l}-z^{h}\right)<0
$$

Second, consider the LHS. Using the same argument as for the RHS, we obtain:

$$
\text { LHS }>\alpha\left(\pi^{h}-\pi^{l}-\left(1-\pi^{l}\right) \frac{z^{l}}{z^{h}}+\frac{z^{h}}{z^{l}}\left(1-\pi^{h}\right)\right)>\alpha\left(z^{h}-z^{l}\right)\left(\frac{1-\pi^{h}}{z^{l}}+\frac{1-\pi^{l}}{z^{h}}\right)>0
$$

By inference, we obtain $C_{k}^{h} z^{h}>C_{k}^{l} z^{l}$ for $k=1, \ldots, n$ if $\pi^{h}+\pi^{l}>1$. The result is true in zero supply and still holds, by continuity, for small bond volumes. $Q E D$.

\section{B.2 Value of the long run interest rate.}

We determine the common value, towards which yields converge in both states. We diagonalize the matrix $M(C, X)$ defined in $(27)$ as $M(C, X)=\beta Q D Q^{-1}$. Matrices $Q$ and $D$ are defined as:

$$
\begin{aligned}
& Q \equiv\left[\begin{array}{lll}
-\frac{\alpha\left(\pi^{h}-\pi^{l}\right)-(\alpha-1)\left(z^{h} u^{\prime h} \pi^{h}-z^{l} u^{l} \pi^{l}\right)-H}{2\left(1-\pi^{l}\right)\left(z^{h} u^{\prime h}(\alpha-1)-\alpha\right)} & -\frac{\alpha\left(\pi^{h}-\pi^{l}\right)-(\alpha-1)\left(z^{h} u^{\prime h} \pi^{h}-z^{l} u^{\prime l} \pi^{l}\right)+H}{2\left(1-\pi^{l}\right)\left(z^{h} u^{\prime h}(\alpha-1)-\alpha\right)} \\
1 & 1
\end{array}\right] \\
& D \equiv \frac{1}{2}\left[\begin{array}{ll}
\alpha\left(\pi^{h}+\pi^{l}\right)+(1-\alpha)\left(z^{h} u^{\prime h} \pi^{h}+z^{l} u^{\prime l} \pi^{l}\right)-H & 0 \\
0 & \alpha\left(\pi^{h}+\pi^{l}\right)+(1-\alpha)\left(z^{h} u^{\prime h} \pi^{h}+z^{l} u^{\prime l} \pi^{l}\right)+H
\end{array}\right] \\
& H \equiv\left[\left(\alpha\left(\pi^{h}+\pi^{l}\right)+(1-\alpha)\left(z^{h} \pi^{h} u^{\prime h}+z^{l} \pi^{l} u^{\prime l}\right)\right)^{2}-4\left(z^{h} u^{\prime h}(1-\alpha)+\alpha\right)\left(z^{l} u^{\prime l}(1-\alpha)+\alpha\right)\left(\pi^{h}+\pi^{l}-1\right)\right]^{1 / 2}
\end{aligned}
$$

(One can check that the term under the square is always positive in the neighborhood of the zero net supply). We can now diagonalize the matrix defining $C^{h}$ and $C^{l}$ and modify the system (23) and iterate it to obtain:

$$
\left[\begin{array}{c}
C_{k}^{h} \\
C_{k}^{l}
\end{array}\right]=\beta^{k} Q \cdot D^{k} \cdot Q^{-1}\left[\begin{array}{c}
C_{0}^{h} \\
C_{0}^{l}
\end{array}\right] \Longrightarrow\left[\begin{array}{c}
P_{k}^{h} \\
P_{k}^{l}
\end{array}\right]=\beta^{k}\left[\begin{array}{cc}
z^{h} & 0 \\
0 & z^{l}
\end{array}\right] Q \cdot D^{k} \cdot Q^{-1}\left[\begin{array}{c}
C_{0}^{h} \\
C_{0}^{l}
\end{array}\right]
$$

Developing the preceding equality allows us to obtain an analytical expression for $P_{k}^{h}$. Remarking that $H>0$, we simplify the expression with $\left(\frac{\alpha\left(\pi^{h}+\pi^{l}\right)-(\alpha-1)\left(z^{h} u^{\prime h} \pi^{h}+z^{l} u^{\prime l} \pi^{l}\right)-H}{\alpha\left(\pi^{h}+\pi^{l}\right)-(\alpha-1)\left(z^{h} u^{\prime h} \pi^{h}+z^{l} u^{\prime l} \pi^{l}\right)+H}\right)^{k} \underset{k \rightarrow \infty}{\longrightarrow} 0$. As a 
consequence, the price $P_{k}^{h}$ verifies:

$$
\begin{aligned}
& \lim _{k \rightarrow \infty} \log \left[P_{k}^{h}\left(\frac{1}{H} 2^{-k-1} \beta^{k}\right)^{-1}\left(\alpha\left(\pi^{h}+\pi^{l}\right)-(\alpha-1)\left(z^{h} u^{\prime h} \pi^{h}+z^{l} u^{\prime l} \pi^{l}\right)+H\right)^{-k}\right] \\
& \quad=\log \left[H-\left(\alpha\left(\pi^{l}-\pi^{h}\right)+(\alpha-1)\left(z^{h} u^{\prime h} \pi^{h}-z^{l} u^{\prime l} \pi^{l}\right)\right)+2\left(\alpha+z^{l} u^{\prime l}(1-\alpha)\right)\left(1-\pi^{h}\right) \frac{z^{h} u^{\prime h}}{z^{l} u^{l}}\right]
\end{aligned}
$$

As $r_{k}^{h}=-\frac{1}{k} \log P_{k}^{h}$, one finally deduces the expression of $r_{k}^{h}$ when its maturity goes to infinity. By a simple symmetry argument, one obtains the same expression for the common limit:

$$
\lim _{k \rightarrow \infty} r_{k}^{h}=\lim _{k \rightarrow \infty} r_{k}^{l}=\widetilde{r}^{\lim }=-\log \beta-\log \frac{\alpha\left(\pi^{h}+\pi^{l}\right)+(1-\alpha)\left(z^{h} u^{\prime h} \pi^{h}+z^{l} u^{\prime l} \pi^{l}\right)+H}{2}
$$

\section{Proof of proposition 2}

\section{C.1 Impact of bond volumes on prices.}

We prove by inference that bond volumes decrease prices and increase yields. We prove the result for $C_{k}^{h}$ and the method is the same for $C_{k}^{l}$. We begin with expressing the derivative of $C_{k}^{h}$ relative to $B_{i}$ for $1 \leq k, i \leq n\left(u^{\prime \prime l}\right.$ and $u^{\prime \prime h}$ are defined in $\left.(28)\right)$ :

$$
\begin{aligned}
\frac{\partial C_{k}^{h}}{\partial B_{i}} & =\alpha \beta\left(\pi^{h} \frac{\partial C_{k-1}^{h}}{\partial B_{i}}+\left(1-\pi^{h}\right) \frac{\partial C_{k-1}^{l}}{\partial B_{i}}\right)+(1-\alpha) \beta\left(\pi^{h} \frac{\partial C_{k-1}^{h}}{\partial B_{i}} z^{h} u^{\prime h}+\left(1-\pi^{h}\right) \frac{\partial C_{k-1}^{l}}{\partial B_{i}} z^{l} u^{\prime l}\right) \\
& +(1-\alpha) \beta \pi^{h} C_{k-1}^{h}\left(z^{h}\right)^{2}\left(\sum_{j=1}^{n} \frac{\partial C_{j-1}^{h}}{\partial B_{i}} B_{j}+C_{i-1}^{h}\right) u^{\prime \prime h} \\
& +(1-\alpha) \beta\left(1-\pi^{h}\right) C_{k-1}^{l}\left(z^{l}\right)^{2}\left(\sum_{j=1}^{n} \frac{\partial C_{j-1}^{l}}{\partial B_{i}} B_{j}+C_{i-1}^{l}\right) u^{\prime \prime l}
\end{aligned}
$$

1. The result holds for $k=1$, since the derivative (32) provides for small bond supply:

$$
\frac{\partial C_{1}^{h}}{\partial B_{i}} \approx(1-\alpha) \beta\left[\pi^{h} C_{k-1}^{h}\left(z^{h}\right)^{2} C_{i-1}^{h} u^{\prime \prime h}+\left(1-\pi^{h}\right) C_{k-1}^{l}\left(z^{l}\right)^{2} C_{i-1}^{l} u^{\prime \prime l}\right]
$$

2. We suppose that the result holds for $k-1$ and $\frac{\partial C_{k-1}^{h}}{\partial B_{i}}, \frac{\partial C_{k-1}^{l}}{\partial B_{i}}<0$. Since $C_{j}^{s}$ is a $\mathcal{C}^{1}$ function of $B_{i}, \frac{\partial C_{j-1}^{s}}{\partial B_{i}}$ is continuous in $B_{i}$ and $B_{j} \frac{\partial C_{j-1}^{s}}{\partial B_{i}}(s=h, l)$ is negligible relative to $C_{i-1}^{s}$ for small bond supply. Eq. (32) implies that $\frac{\partial C_{k}^{h}}{\partial B_{i}}<0$. Larger bond supply decreases prices. $Q E D$.

\section{C.2 Impact of bond volumes on the slope.}

We prove that larger bond volumes steepen the curve. Using the expression (31) of $\widetilde{r}^{\text {lim }}$ and the one of $r_{1}((24)$ and the price structure $(23))$, the derivative of the slope relative to $B_{j}$ for $j \leq n$ 
expresses as:

$$
\begin{aligned}
\frac{\partial}{\partial B_{j}} \Delta= & (1-\alpha) \frac{\left(1-\pi^{h}\right)\left(1-\pi^{l}\right)\left(z^{h}-z^{l}\right)}{2-\pi^{h}-\pi^{l}} \times\left(\frac{z^{l}}{\pi^{l} z^{h}+\left(1-\pi^{l}\right) z^{l}} \frac{\partial u^{l}}{\partial B_{j}}-\frac{z^{h}}{\left(1-\pi^{h}\right) z^{h}+\pi^{h} z^{l}} \frac{\partial u^{\prime h}}{\partial B_{j}}\right) \\
& +O\left((1-\alpha)^{2}\right)
\end{aligned}
$$

with (we also give expressions when the bond supply is close to 0 ):

$$
\begin{aligned}
\frac{\partial}{\partial B_{j}} u^{\prime h} & =z^{h}\left(\sum_{k=1}^{n} \frac{\partial C_{k}^{h}}{\partial B_{j}} B_{k+1}+C_{j-1}^{h}\right) u^{\prime \prime}\left(\delta+B_{1}+z^{h} \sum_{k=1}^{n} C_{k}^{h} B_{k+1}\right) \approx z^{h} C_{j-1}^{h} u^{\prime \prime}(\delta) \\
\frac{\partial}{\partial B_{j}} u^{\prime l} & =z^{l}\left(\sum_{k=1}^{n} \frac{\partial C_{k}^{l}}{\partial B_{j}} B_{k+1}+C_{j-1}^{l}\right) u^{\prime \prime}\left(\delta+B_{1}+z^{l} \sum_{k=1}^{n} C_{k}^{l} B_{k+1}\right) \approx z^{l} C_{j-1}^{l} u^{\prime \prime}(\delta)
\end{aligned}
$$

The sign of $\frac{\partial}{\partial B_{j}} \Delta$ depends on the sign of $A \equiv \frac{z^{l}}{\pi^{l} z^{h}+\left(1-\pi^{l}\right) z^{l}} \frac{\partial u^{\prime l}}{\partial B_{j}}-\frac{z^{h}}{\left(1-\pi^{h}\right) z^{h}+\pi^{h} z^{l}} \frac{\partial u^{\prime h}}{\partial B_{j}}$. Substituting the derivatives by their values allows to express $A$ when bond supply is close to 0 as:

$$
\tilde{A}=\left(\frac{z^{l}}{\pi^{l}\left(z^{h}-z^{l}\right)+z^{l}} C_{j-1}^{l} z^{l}-\frac{z^{h}}{\pi^{h}\left(z^{l}-z^{h}\right)+z^{h}} C_{j-1}^{h} z^{h}\right) u^{\prime \prime}(\delta)
$$

As $z^{h}>z^{l}$, a sufficient condition for $\tilde{A}$ to be positive is $C_{j-1}^{h} z^{h}>C_{j-1}^{l} z^{l}$, which is always true. Thus, bond volumes increase the slope of the curve as soon as $\pi^{h}+\pi^{l}>1$. QED.

\section{Proof of proposition 3}

We prove that: (i) ex ante welfare increases with bond supply and (ii) at date 0 , the welfare of $e u$ and $u u$ goes only if the discount factor $\beta$ is large enough. We suppose that there is no aggregate shock and $z_{t}=1$. We note $U$ the vector of instantaneous utility. Using budget constraints, it expresses as:

$$
U=\left[\begin{array}{c}
u\left(c^{e e}\right)-l^{e e} \\
u\left(c^{u e}\right)-l^{u e} \\
u\left(c^{e u}\right)-l^{e u} \\
u\left(c^{u u}\right)-l^{u u}
\end{array}\right]=\left[\begin{array}{c}
u\left(u^{\prime-1}(1)\right)-1 \\
u\left(u^{\prime-1}(1)\right)-1-\sum_{k=1}^{n} C_{k-1} B_{k} \\
u\left(\delta+\sum_{k=1}^{n} C_{k-1} B_{k}\right) \\
u(\delta)
\end{array}\right]
$$

The transition matrix $\Omega$ for the four states $\{$ ee ue eu $u u\}$ of the economy is the following:

$$
\Omega=\left[\begin{array}{cccc}
\alpha & 0 & 1-\alpha & 0 \\
\alpha & 0 & 1-\alpha & 0 \\
0 & 1-\rho & 0 & \rho \\
0 & 1-\rho & 0 & \rho
\end{array}\right]=Q \cdot D \cdot Q^{-1}, \text { with } Q=\left[\begin{array}{cccc}
1 & 1-\alpha & 0 & 1-\alpha \\
1 & 0 & \rho & 1-\alpha \\
1 & -\alpha & 0 & -(1-\rho) \\
1 & 0 & -(1-\rho) & -(1-\rho)
\end{array}\right]
$$

and $D=\operatorname{Diag}\left(\begin{array}{llll}1 & 0 & 0 & \alpha \\ & +\rho-1)\end{array}\right.$. 
The vector $\mathcal{U}$ of the four intertemporal utilities is $\mathcal{U}=\sum_{k=0}^{\infty} \beta^{k} \Omega^{k} U=\sum_{k=0}^{\infty} \beta^{k} Q D^{k} Q^{-1} U$

The impact of a bond increase $B_{k}$ on this intertemporal utility $\mathcal{U}$ is:

$$
\frac{\partial \mathcal{U}}{\partial B_{k}}=\left[\begin{array}{c}
\frac{\partial \mathcal{U}^{e e}}{\partial B_{k}} \\
\frac{\partial \mathcal{U}^{u e}}{\partial B_{k}} \\
\frac{\partial \mathcal{U}^{e u}}{\partial B_{k}} \\
\frac{\partial \mathcal{U}^{u u}}{\partial B_{k}}
\end{array}\right]=C_{k-1} Q \cdot\left[\begin{array}{cccc}
\frac{1}{1-\beta} & 0 & 0 & 0 \\
0 & 1 & 0 & 0 \\
0 & 0 & 1 & 0 \\
0 & 0 & 0 & \frac{1}{1-\beta(\alpha+\rho-1)}
\end{array}\right] \cdot Q^{-1}\left[\begin{array}{c}
0 \\
-1 \\
u^{\prime}\left(\delta+\sum_{k=1}^{n} C_{k-1} B_{k}\right) \\
0
\end{array}\right]
$$

First, the first part of the proposition stems directly from the impact of bond supply on instantaneous utility. Whereas in the states ee and $u u$, the utility does not change, it decreases from -1 in $u e$ and goes up from $u^{\prime}=u^{\prime}\left(\delta+\sum_{k=1}^{n} C_{k-1} B_{k}\right)$ in $e u$. Since our equilibrium exists only if $u^{\prime}=u^{\prime}\left(\delta+\sum_{k=1}^{n} C_{k-1} B_{k}\right)>1$, and that $e u$ and $u e$ states are equally probable, ex ante welfare always increases with bond supply.

To obtain the second part of the result, we expand the preceding expression of $\frac{\partial \mathcal{U}}{\partial B_{k}}$ :

$$
\frac{\partial \mathcal{U}}{\partial B_{k}}=\frac{C_{k-1}}{(2-\alpha-\rho)(1-\beta)(1-\beta(\alpha+\rho-1)}\left[\begin{array}{c}
\beta(1-\alpha)\left(u^{\prime}-\beta\left(1+\rho\left(u^{\prime}-1\right)\right)\right) \\
(1-\beta \rho)\left(\beta\left(\alpha+(1-\alpha) u^{\prime}\right)-1\right) \\
(1-\beta \alpha)\left(u^{\prime}-\beta\left(1+\rho\left(u^{\prime}-1\right)\right)\right) \\
\beta(1-\rho)\left(\beta\left(\alpha+(1-\alpha) u^{\prime}\right)-1\right)
\end{array}\right]
$$

Noting $\beta_{0}=\left[\alpha+(1-\alpha) u^{\prime}\left(\delta+\sum_{k=1}^{n} C_{k-1} B_{k}\right)\right]^{-1}$, it is straightforward to prove that if $\beta>\beta_{0}$, the expected welfare of all agents' types increases with $B_{k}$ and if $\beta<\beta_{0}$, that the welfare of $u e$ and $u u$ decreases. 